\title{
In Vitro Antimicrobial Activities against Streptococcus Mutans: A Comparative Study of Green Versus Black Tea Extracts and $0.2 \%$ Chlorhexidine and Fluoride
}

\author{
Najmeh Akhlaghi ${ }^{1^{\star}}$, Maryam Mehnati², Maryam Hajiahmadi ${ }^{3}$ \\ 1DDS, MS, Assistant Professor, Dental Research Center, Department of Pediatric Dentistry, \\ School of Dentistry, Isfahan University of Medical Sciences, Isfahan, Iran. \\ 2DDS, School of Dentistry, Isfahan University of Medical Sciences, Isfahan, Iran. \\ 3DDS, MS, Assistant Professor, Dental Research Center, Department of Pediatric Dentistry, \\ School of Dentistry, Isfahan University of Medical Sciences, Isfahan, Iran.
}

\begin{abstract}
Introduction: The aim of the present study was to evaluate and compare the antibacterial effects of black and green tea extracts with those of $0.2 \%$ sodium fluoride and chlorhexidine (CHX) mouth rinse on SM in- vitro.

Methods: In this in-vitro study the effects of fluoride and $\mathrm{CHX}$ mouth rinse, black and green tea extracts on SM PTCC 1683 were evaluated and compared using the minimal inhibitory concentration (MIC), minimal bactericidal concentration (MBC) technique and disk diffusion method by measuring the diameters of inhibition zones. Descriptive statistics were retrieved and data was analyzed using Mann-Whitney and Kruskal-Wallis analysis. Statistical significance level was established at $p<0.05$.

Results: MIC and MBC of black and green tea extracts were similar $(62.5 \mathrm{mg} / \mathrm{mL})$, with 0.125 and $2 \mathrm{mg} / \mathrm{mL}$ for $\mathrm{CHX}$ and fluoride, respectively. The inhibition zones for pure green and black tea extracts and $\mathrm{CHX}$ were 16.05, 11.77 and $9.91 \mathrm{~mm}$, respectively. The green tea had the larger inhibition zone than $\mathrm{CHX}$ and fluoride. ( $\mathrm{P}$ value $<0.01$ ) There was no significant difference between green and black tea. $(P$ value $=0.23$ )

Conclusion: The green and black tea had similar antibacterial effect on 62.5 to $1000 \mathrm{mg} / \mathrm{ml}$ concentrations. The anti SM
\end{abstract}

\section{INTRODUCTION}

Streptococcus bacterial species is one of the main factors initiating dental caries. ${ }^{1}$ Since dental caries is a multifactorial condition, preventive techniques use combined methods, including nutritional counseling, observation of oral hygiene using mechanical and chemical methods, etc. The most common chemical method is the use of mouth rinses such as sodium fluoride or chlorhexidine $(\mathrm{CHX}){ }^{2} \mathrm{CHX}$ nonspecifically decreases the counts of useful and pathogenic bacteria; however, it has complications such as discoloration of teeth and the tongue and irritation of the mucosa, also its use and acceptance by young children is a major challenge. ${ }^{3}$

New caries preventive techniques have focused on the use of safe natural substances with anticariogenic properties, including plant- activity of $\mathrm{CHX}$ and fluoride appears on a lower concentration than green and black tea extracts. However, the inhibitory effect of green tea at higher concentration was significantly more than $\mathrm{CHX}$ and fluoride. In general, the antibacterial effects of green tea, black tea and $\mathrm{CHX}$ were significantly higher than fluoride.

Key Words: Chlorhexidine, Streptococcus mutans, Green Tea, Black Tea, Sodium fluoride.

\section{${ }^{*}$ Correspondence to:}

Maryam Hajiahmadi, DDS, MS [Assistant Professor],

Dental Research Center, Department of Pediatric Dentistry, Isfahan University of Medical Sciences, Isfahan, Iran.

\section{Article History:}

Received: 27-08-2016, Revised: 29-08-2016, Accepted: 16-09-2016

\begin{tabular}{|l|c|}
\hline \multicolumn{2}{|c|}{ Access this article online } \\
\hline Website: & Quick Response code \\
www.ijmrp.com & \\
\hline DOI: & \\
10.21276/ijmrp.2016.2.5.003 & \\
\hline
\end{tabular}

based extracts containing polyphenols, such as tea. ${ }^{4-7}$ Tea is prepared from the leaves of the plant Camellia sinensis. There are three kinds of tea: non-fermented (green tea), semi-fermented (oolong tea) and fermented tea (black tea). ${ }^{8-13}$ Studies carried out on the effect of green tea on SM are numerous but studies on black tea as one of the most commonly used drinks all over the world, especially in Iran, are limited and there are contradictory reports in relation to the comparison of the antibacterial effects of green and black tea. ${ }^{8,10,14}$ Use of tea by young children is much easier than $\mathrm{CHX}$ and fluoride, it is safe, and swallowing it has no systemic side effects. ${ }^{15}$ The aim of the present study was to evaluate and compare the antibacterial effects of green and black tea extracts with $0.2 \% \mathrm{CHX}$ and fluoride on $\mathrm{SM}$ in vitro. 


\section{MATERIALS AND METHODS}

This experimental design, in vitro lab setting study was approved by Isfahan University of Medical Science Ethics Committee; Isfahan, Iran (Project No. 3937179). It was performed in the School of Pharmacy and Dental Research Center of Dentistry Faculty from May to June 2015. Pure cultures of SM (PTCC 1683), were achieved from the Department of Microbiology.

In the present study, $0.2 \%$ sodium fluoride (Behsa, Arak, Iran), $0.2 \%$. CHX (Nazhou, Tehran, Iran) mouth rinses were used.

TSB (Tripticase Soy Broth) (Difco Laboratories, Detroit, MI USA) was used for serial dilutions of extracts, $\mathrm{CHX}$ and fluoride mouth rinse to determine the minimal inhibitory concentration (MIC). Disk diffusion method was used to determine the diameters of inhibition zones and solid blood agar culture medium (HIME DIA., India) was used to determine minimal bactericidal concentration (MBC).

Preparation of extracts: Green and black tea samples (Golestan, Iran) were powdered using an electric mill in order to completely extract the constituents of the plant. Samples were pure without any aromatic or additive materials. Extracting processes were carried out in the Faculty of Pharmaceutics, Isfahan University of Medical Sciences, Isfahan, Iran, using the percolator technique by a pharmacologist. A total of $500 \mathrm{~g}$ of the powdered plant was placed in a percolator, at the end of which a piece of cotton had been placed. Then $70 \%$ ethanol (Merck, Germany) was continuously added to it as a solvent and as the first drops of the solvent exited the percolator, the evacuation tap was closed and the percolator was stored in the laboratory for 24 hours. After 24 hours the evacuation tap of the percolator was opened. The extraction procedure continued until the fluid exiting the percolator was without any color. The exit rate of the extract from the percolator was adjusted at one $\mathrm{mL} / \mathrm{min}$ for $500 \mathrm{~g}$ of the plant powder. All the containers containing the extract were covered with aluminum foils to present the detrimental effects of light and evaporation of the solvent during the extracting procedures.

Determination of phenolic constituents in the extracts: Total phenolic content in the ethanolic tea leaf extracts of $C$. sinensis was determined by the Folin-Ciocalteau colorimetric method. ${ }^{16} \mathrm{~A}$ total of $20 \mathrm{~mL}$ of tea extracts, blank and standard solutions were poured into test tubes and $100 \mu \mathrm{L}$ of the reagent folin siocalto and $1.58 \mathrm{~mL}$ of distilled water were added to each test tube and properly mixed. Then $300 \mathrm{~mL}$ of saturated sodium carbonate solution was added to each test tube and stored at $25^{\circ} \mathrm{C}$ for 120 minutes in a dark environment. Then, a UV spectrophotometer was used to determine the optical density (OD) of each sample at a wavelength of $765 \mathrm{~nm}$ compared to the blank. The standard concentration curve of phenolic compounds was prepared with the use of the $\mathrm{OD}$ of standard gallic acid versus their concentrations. The total phenolic compositions of the extracts were determined using the standard curve equation and the $\mathrm{OD}$ the plant extracts $\left(R^{2}=0.9899 ; Y=0.0007 X+0.038\right)$.

The overall polyphenol contents of green and black tea were 8.1 $\mathrm{mg} / \mathrm{ml}$ and $6.32 \mathrm{mg} / \mathrm{ml}$, respectively. All the pure phenolic extracts were stored in refrigerators at $4^{\circ} \mathrm{C}$ and transported to the Dental Research Center of Dentistry Faculty.

Determination of MIC and MBC using the agar dilution method: The agar dilution method recommended by the NCCLS standards (National Committee for Clinical Laboratory Standards) was used. ${ }^{17}$
$100 \%, 50 \%, 25 \%, 12.5 \%, 6.25 \%, 3.12 \%, 1.56 \%$ and $0.75 \%$ concentrations of each extract were prepared. These concentrations are equal to $1000,500,250,125,62.5,31.25$, 15.625 and $7.6 \mathrm{mg} / \mathrm{mL}$, respectively.

One $\mathrm{mL}$ of the microbial suspension containing $1.5 \times 10^{8} \mathrm{CFU} / \mathrm{mL}$ ( $0.5 \mathrm{McF}$ arland turbidity standards) of bacterial sample was added to each test tube.

The test tubes were incubated at $37^{\circ} \mathrm{C}$ for 24 hours and the results were evaluated in terms of turbidity of the test tubes compared to the time before incubation and the positive and negative controls. After incubation, the minimum concentration of each extract that resulted in the inhibition of bacterial growth was considered as MIC.

The turbidity in each test tube indicated the inefficacy of that concentration in inhibiting bacterial growth. Subsequent to determination of MIC, approximately $50 \mu \mathrm{L}$ of the solutions from test tubes with no turbidity were transferred onto the solid blood agar culture plates (HIME DIA., India) and cultured with a swab using the spread plate method, followed by incubation at $37^{\circ} \mathrm{C}$ for 48 hours to determine the presence or absence of bacterial growth macroscopically (observing the colonies by a microbiologist). The minimum concentration in which no bacterial proliferation was detected (no colonies) was reported as MBC. Each examination was tested seven times by one microbiologist. In relation to determination of MIC it should be pointed out that due to the turbid nature of the extracts used in the present study and the inability to determine the accuracy of turbidity or clarity of the test tubes after incubation, microbial plates were prepared from the turbid test tubes and evaluated under a microscope to evaluate the growth or inhibition of growth of bacteria.

The culture medium along with the strain was considered the negative control and the tube with $S M$ and penicillin was the positive control.

Disk diffusion method to determine the diameters of the inhibition zones: Spread plate method was used to prepare a culture from the bacterial suspension at $0.5 \mathrm{McF}$ arland concentrations on blood agar. After 5-10 minutes, wells measuring six $\mathrm{mm}$ in diameter were prepared in the culture and the bottoms of the wells were sealed with blood agar medium; the distance between the wells and the edge of the plate was $1.5 \mathrm{~cm}$ and the wells were $2-2.5 \mathrm{~cm}$ apart. Then $50-100 \mu \mathrm{L}$ of the pure concentrations of the extracts and $0.2 \%$ fluoride and $\mathrm{CHX}$ were transferred into the wells. The negative and positive control wells were filled with physiologic serum and $10 \mu \mathrm{g}$ of penicillin, respectively. The plates were placed in a refrigerator for 1-2 hours to provide the antimicrobial agent with the opportunity to diffuse into the environment. The plates were incubated at $37^{\circ} \mathrm{C}$ for 18-24 hours. Then Vernier calipers were used to determine the diameters of the zones of inhibition. This test was repeated separately seven times for each material by one microbiologist who also examined the MIC and MBC.

Statistical Analysis: Statistical analysis was done using the software SPSS (version 20, Chicago, IL, USA). Descriptive statistics were retrieved and data of the inhibition zones was was compared using Kruskall-Wallis followed by Mann-Whitney $U$ test for pairwise comparison Statistical significance level was established at $p<0.05$. 
Table1: MIC, MBC and Inhibition Zone of extracts, Chlorhexidine and Sodium fluoride $\mathbf{0 . 2 \%}$.

\begin{tabular}{lccc}
\hline & $\begin{array}{c}\text { MIC } \\
(\mathrm{mg} / \mathrm{ml})\end{array}$ & $\begin{array}{c}\text { MBC } \\
(\mathrm{mg} / \mathrm{ml})\end{array}$ & $\begin{array}{c}\text { Inhibition Zone of pure concentration } \\
\text { mean }(\mathrm{mm})\end{array}$ \\
\hline Green Tea & 62.5 & 62.5 & 16.05 \\
Black Tea & 62.5 & 62.5 & 11.8 \\
Chlorhexidine $0.2 \%$ & 0.125 & 0.125 & 9.92 \\
Sodium fluoride $0.2 \%$ & 2 & 2 & $\mathbf{0}$ \\
\hline
\end{tabular}

Minimal inhibitory concentration (MIC); Minimal bactericidal concentration (MBC);

$\mathrm{mg} / \mathrm{ml}$ : milligram /milliliter; mm: millimeter

Table 2: Mean of Inhibition zone ( $\mathrm{mm}$ ) in different concentrations of green and black tea, fluoride and chlorhexidine

\begin{tabular}{lrrrrrc}
\hline Materials & \multicolumn{7}{c}{ Concentrations } \\
\cline { 2 - 7 } & $\mathbf{1 0 0 \%}$ & $\mathbf{5 0 \%}$ & $\mathbf{2 5 \%}$ & $\mathbf{1 2 . 5 \%}$ & $\mathbf{6 . 2 5} \%$ & $\begin{array}{c}\text { Penicillin } \\
\text { (positive control) }\end{array}$ \\
Green Tea & 16.05 & 14.05 & 11.98 & 9.93 & 7.98 & $\mathbf{1 5 . 1 2}$ \\
Black Tea & 11.8 & 10.1 & 8.02 & 5.87 & 4.05 & $\mathbf{1 5 . 1 2}$ \\
Fluoride $0 . \mathbf{0 . 2} \%$ & 0 & 0 & 0 & 0 & 0 & 15 \\
Chlorhexidine $0.2 \%$ & 9.92 & 7.95 & 5.96 & 3.96 & 1.92 & 15 \\
\hline
\end{tabular}

Table 3: Inhibition zone analysis in different concentrations of green and black tea, fluoride and chlorhexidine. Small letters represent a comparison of various concentrations of each substance (vertical comparison). Large letters indicate comparison of different materials in each concentration (horizontal comparison)

\begin{tabular}{lcccc}
\hline Concentration $\%$ & Green tea & Black tea & Fluoride $\mathbf{0 . 2} \%$ & Chlorhexidine $\mathbf{0 . 2 \%}$ \\
\hline $6 / 25$ & $\mathrm{Aa}$ & $\mathrm{Aa}$ & $\mathrm{Ca}$ & $\mathrm{Ba}$ \\
$12 / 5$ & $\mathrm{Aa}$ & $\mathrm{Aa}$ & $\mathrm{Ca}$ & $\mathrm{Ab}$ \\
25 & $\mathrm{Aa}$ & $\mathrm{Aa}$ & $\mathrm{Aa}$ & $\mathrm{Ac}$ \\
50 & $\mathrm{Ac}$ & $\mathrm{Ab}$ & $\mathrm{Ba}$ & $\mathrm{Ad}$ \\
100 & $\mathrm{Ab}$ & $\mathrm{Ac}$ & $\mathrm{Ca}$ & $\mathrm{Ae}$ \\
\hline
\end{tabular}

\section{RESULTS}

Table 1 summarizes the MIC, MBC and the mean diameters of the inhibition zones for black and green tea extracts, $\mathrm{CHX}$ and fluoride mouth rinse. The MIC, MBC results were the same in all seven times of examinations.

MIC and MBC: The green and black tea had an antibacterial effect on 62.5 to $1000 \mathrm{mg} / \mathrm{ml}$ concentrations. MIC for green and black tea was achieved at $62.5 \mathrm{mg} / \mathrm{mL}$, i.e. the minimal concentration of green and black tea that inhibited bacterial growth was $62.5 \mathrm{mg} / \mathrm{mL}$. At concentrations less than $62.5 \mathrm{mg} / \mathrm{mL}$ the test tubes were not clear compared to the time before incubation and turbidity was observed due to bacterial growth. At concentrations higher than $62.5 \mathrm{mg} / \mathrm{mL}$ the test tubes were clear compared to the time before incubation, indicating that the concentration was able to inhibit bacterial growth.

However, the MIC and MBC of tea extracts were higher than $\mathrm{CHX}$ $(0.125 \mathrm{mg} / \mathrm{mL})$ and fluoride $(2 \mathrm{mg} / \mathrm{mL})$. After determination of MIC for each extract and transfer of each clear test tube onto the solid blood agar plates to determine MBC, the following results were observed. By observing or not observing any bacterial colonies on the blood agar culture media, MBC for tea extracts was determined at $62.5 \mathrm{mg} / \mathrm{mL}$, i.e. the minimum concentration of the material that destroyed the bacteria was $62.5 \mathrm{mg} / \mathrm{mL}$, at which no bacterial colonies were observed.
The MIC and MBC of $\mathrm{CHX}$ were similar $(0.125 \mathrm{mg} / \mathrm{mL})$. MIC and $\mathrm{MBC}$ of fluoride were similar as well. (2 $\mathrm{mg} / \mathrm{mL})$

Considering seven measurements made for MIC and MBC and the similarity of all the values in each sample (with a variance of zero for the values), there were not significant differences between MIC and MBC of each sample $(P=1)$. The correlation coefficient for MIC and MBC values in all the materials was the same $(r=1, P<0.01)$.

Results of the disk diffusion method: The diameter of the inhibition zone (mean) for pure green and black tea (100\%) was $16.05 \mathrm{~mm}, 11.8 \mathrm{~mm}$ respectively with $9.92 \mathrm{~mm}$ for $0.2 \% \mathrm{CHX}$ mouth rinse. Bacterial growth was not inhibited around the fluoride mouth rinse and the diameter of inhibition zone was zero.

The comparison of the diameter of inhibition zone in each concentration $(62.5-100 \mathrm{mg} / \mathrm{ml})$ of green tea and $\mathrm{CHX}$ revealed significant differences. ( $P$ value $=0.01$ ) Furthermore the difference between various concentrations of green tea and fluoride was significant. ( $P$ value $<0.001)$ All concentrations $(62.5-1000 \mathrm{mg} / \mathrm{ml})$ of black tea showed significant difference with fluoride. ( $P$ value $=0.001)$ The difference between each concentration of chlorhexidine and fluoride was significant. $(P$ value $=0.03)$ The results of the inhibition zone at 62.5 to $1000 \mathrm{mg} / \mathrm{ml}$ concentrations of each substance have been summarized in Table 2 . 
In this concentration range, the diameter of inhibition zone of the green tea was larger than the black tea; however there was no significant difference. ( $P$ value $=0.23$ ) There was no significant difference between inhibition zone of the black tea and $\mathrm{CHX}$ as well. $(P$ value $=0.08)$

\section{DISCUSSION}

In the present study the green and black tea extracts had an antibacterial effect on 62.5 to $1000 \mathrm{mg} / \mathrm{ml}$ concentrations. The results showed that the MIC and MBC of green and black tea extracts were similar $(62.5 \mathrm{mg} / \mathrm{mL})$. In other words, green and black tea cannot completely inhibit $S M$ until they reach a concentration of $62.5 \mathrm{mg} / \mathrm{mL}$. However, the MIC and MBC of tea extracts were higher than $\mathrm{CHX}(0.125 \mathrm{mg} / \mathrm{mL})$ and fluoride $(2$ $\mathrm{mg} / \mathrm{mL}$ ). It means that the anti $\mathrm{SM}$ activity of $\mathrm{CHX}$ and fluoride appears on a lower concentration than green and black tea extracts. These findings are in agreement with Thomas et al. 6 Base on MIC analysis against SM, they confirmed that chlorhexidine mouth rinse was found to be the most effective as compared to sodium fluoride, fluoride with essential oils and green tea. $(P<0.001)$

The antibacterial effects of green and black tea extracts were found to be similar in the present study. Contradictory, Naderi et al 18 reported that the MIC of green and black tea was 150 and 50 $\mathrm{mg} / \mathrm{ml}$, respectively. They concluded that the anti SM activity of black tea appears on a lower concentration than green tea. The conflicting results of two studies could be due to differences in the type of tea (Lahijan vs Golestan,Iran) and the strain of SM.

The diameters of inhibition zones for pure green and black tea (16.05 and $11.8 \mathrm{~mm}$ ) were higher than $\mathrm{CHX}(9.91 \mathrm{~mm})$ and fluoride $(0 \mathrm{~mm})$, which means bacterial growth in the presence of pure tea extract was less than that of $\mathrm{CHX}$.

In the present study, $0.2 \%$ fluoride mouth rinse was unable to inhibit bacterial growth in the plate well technique, which might be attributed to the exposure time and the bacterial strain involved.

The inhibition zone analysis showed that the anti-SM effect of green tea on higher concentration $(6.25-100 \%)$ was significantly more than $0.2 \% \mathrm{CHX}$ and fluoride. At these concentrations, the anti SM activity of green and black tea was similar and there was no significant difference. In general, the antibacterial effects of green tea, black tea and $\mathrm{CHX}$ were significantly higher than fluoride.

These findings are in agreement with the previous studies which concluded that the green tea has an inhibitory effect on SM.19,20 Subramaniam et al ${ }^{21}$ demonstrated that the extract of green tea showed greater zone of inhibition than $\mathrm{CHX}$ and black tea. Anita et al 7 reported that MIC and MBC of green tea extract on SM was found to be $0.2 \%$ and $0.8 \%$ respectively. The mean zone of inhibition for green tea was $18.33 \mathrm{~mm}$.

Studies carried out on the effect of green tea on SM are numerous but studies on black tea as one of the most commonly used drinks all over the world, especially in Iran, are limited and there are contradictory reports in relation to the comparison of the antibacterial effects of green tea and black tea. ${ }^{11,13}$

In the present study, the inhibitory effects of green and black tea were similar. On the contrary, Smullen et al ${ }^{22}$ showed that green tea has a great effect on inhibiting SM compared to black tea because green tea has a higher content of catechin. Rasheed and Haider $^{23}$ suggested that the antibacterial effect of black tea was not reported to be higher than that of green tea and as a result of fermentation, the antibacterial activity of black tea changes.

Contrary to the studies above, Hamidi et al ${ }^{11}$ and Naderi et al ${ }^{18}$ reported a higher antimicrobial activity of black tea on oral SM and inhibition of biofilm formation than that of green tea.

The major difference between the green tea and black tea is in their content of catechin which is a type of polyphenol. These black and large materials are converted to theaflavin and thearubigin during the manufacturing of black tea, referred to as fermentation. ${ }^{9}$

A cup of green tea which has been prepared in a conventional manner contains $0.5-1 \mathrm{~g}$ of catechin, while black tea contains one-third of the amount mentioned above. The antibacterial effect of black tea is attributed to the presence of thiaflavin and galic acid in its chemical structure. ${ }^{12}$

The volatile components of tea that are found in small amounts (10-20 ppm) have antimicrobial activity and are found in higher concentrations in black tea compared to green tea. ${ }^{14}$

Studies have shown that tea, especially green tea, has a role in preventing dental caries through inhibition of bacterial proliferation, prevention of bacterial adhesion to tooth enamel, inhibition of bacterial enzymes glycosyl transferase and amylase.5,14 Other pieces of evidence have shown that catechin in tea alters the phenotype of SM and prevents its adhesion to tooth surfaces. ${ }^{22}$

According to the above explanations, similar antibacterial effects of green and black tea as a results of the present study, seems to be reasonable.

It is difficult to directly compare the results of different studies due to differences in methods used to analyze the results, the strains of $S M$, the presence of sucrose in the culture broth, the sources available, the types of the materials and manufacturers and the techniques used to prepare extracts. As discussed above, in the present study the routine tea samples available in Iran were evaluated. Anyway during the process of preparing extracts all or some of the their active ingredients might become inactivated or the concentration of active ingredient might be different due to differences in the location, season or cultivating conditions, affecting the efficacy of tea extract.

Jazaeri et $\mathrm{al}^{4}$ demonstrated that the anti-cariogenic effect of fluoride-chlorhexidine was the higher than green tea in an in vitro study. Although green tea showed higher cariostatic effects than normal saline, in comparison with other mouth rinses, it is less effective.

One of the limitations of the present study was that the biofilm counterpart was not performed and only the anti-SM activity of materials was considered.

However an in vitro study showed that the polyphenols in tea have no effect on remineralization of enamel and the anticariogenic effect of tea is only related to its antibacterial activity. ${ }^{24}$

Based on the results of the present study and by taking account of the fewer side effects of green and black tea compared to $\mathrm{CHX}$ mouth rinses, it appears that tea extracts can be used as economical and suitable adjuvant to synthetic compounds for dental caries prevention, especially in developing economies. ${ }^{16,25}$ In vivo studies in this area are further required as limited data are available regarding the biofilm counterpart. Hence, further studies are required for understanding antimicrobial effect of tea extract in biofilm. 


\section{CONCLUSION}

The green and black tea had similar antibacterial effect on 62.5 to $1000 \mathrm{mg} / \mathrm{ml}$ concentrations. Based on MIC/MBC analyses, the anti $S M$ activity of $\mathrm{CHX}$ and fluoride appears on a lower concentration than green and black tea extracts. However, the inhibition zone analysis showed that the anti-SM effect of green tea on higher concentration (6.25-100\%) was significantly more than chlorhexidine and fluoride. At these concentrations, the black tea inhibited SM more than fluoride. In general, the antibacterial effects of green tea, black and chlorhexidine were significantly higher than fluoride.

\section{ACKNOWLEDGMENTS}

The authors are grateful to Dr. Bahram Soleimani for his valuable aids in statistical analyses and study design, Prof. Ardeshir Talebi and Farzane Amini for microbiological analyses and also Prof Sadeghi for pharmacological analyses. This study was based on a thesis to be submitted to Dental School and was funded by Vise Chancellery for Research and Dental Research Center (Project No. 3937179 IUMS).

\section{REFERENCES}

1. Ansai $T$, Tahara A, Ikeda M, Katoh $Y$, Miyazaki $H$, Takehara $T$. Influence of colonization with mutants streptococci on caries risk in Japanese preschool children: 24 month survival analysis. Pediatric dentistry. 2000; 22(5):377-80.

2. Tinanoff $\mathrm{N}$, Kanellis MJ, Vargas $\mathrm{CM}$. Current understanding of the epidemiology, mechanism and prevention dental caries in preschool children. Pediatr Dent 2002; 24:543-51.

3. Harini PM, Anegundi RT. Efficacy of a probiotic and chlorhexidine mouth rinses: a short-term clinical study. J Indian Soc Pedod Prev Dent 2010 28(3):179-82.

4. Jazaeri M, Pakdek F, Rezaei-Soufi L, Abdolsamadi H, Rafieian N. Cariostatic effect of green tea in comparison with common anticariogenic agents: an in vitro study. J Dent Res Dent Clin Dent Prospects. 2015;9(1):44-8.

5. Siddiqui MW, Sharangi AB, Singh JP, Thakur PK, Ayala-Zavala JF, Singh $A$, et al. Antimicrobial Properties of Teas and Their Extracts in vitro. Crit Rev Food Sci Nutr. 2016;56(9):1428-39

6. Thomas A, Thakur S, Mhambrey S. Comparison of the antimicrobial efficacy of chlorhexidine, sodium fluoride, fluoride with essential oils, alum, green tea, and garlic with lime mouth rinses on cariogenic microbes. J Int Soc Prev Community Dent2015;5(4):302-8.

7. Anita P, Sivasamy S, Madan Kumar PD, Balan IN, Ethiraj S. In vitro antibacterial activity of Camellia sinensis extract against cariogenic microorganisms. J Basic Clin Pharm. 2014;6(1):35-9.

8. Lauten JD, Boyd L, Hanson MB, Lillie D, Gullion C, Madden TE. A clinical study: Melaleuca, Manuka, Calendula and green tea mouth rinse. Phytother Res. 2005; 19(11):951-7.

9. Kawarai T, Narisawa N, Yoneda S, Tsutsumi Y, Ishikawa J, Hoshino $Y$ and et al. Inhibition of Streptococcus mutans biofilm formation using extracts from Assam tea compared to green tea. Arch Oral Biol. 2016;68:73-82.

10. Thomas A, Thakur SR, Shetty SB. Anti-microbial efficacy of green tea and chlorhexidine mouth rinses against Streptococcus mutans, Lactobacilli spp. and Candida albicans in children with severe early childhood caries: A randomized clinical study. J Indian Soc Pedod Prev Dent. 2016;34(1):65-70.

11. Hamdi K, Shoa Hasani AR, Ordouzadeh N, Ghaemi A. The effect of black and greentea extracts on dental-plaque forming Streptococci. Shahrekord Uni Med Sci J 2008;10(3):1-8.
12. Mahmood T, Akhtar N, Khan BA. The morphology, characteristics, and medicinal properties of Camellia sinensis' tea. J Med Plants Res 2010: 4(19): 2028-33.

13. Hassani AS, Amirmozafari N, Ordouzadeh N, Hamdi K, Nazari R, Ghaemi A. Volatile components of Camellia sinensis inhibit growth and biofilm formation of oral streptococci in vitro. Pak J Biol Sci 2008 15;11(10):1336-41.

14. Zhang J, Kashket S. Inhibition of salivary amylase by black and green teas and their effects on the intra oral hydrolysis of starch. Caries Res 1998; 32:233-238.

15. Tehrani MH, Asghari GH, Hajiahmadi M. Comparing Streptococcus mutans and Lactobacillus colony count changes following green tea mouth rinse or sodium fluoride mouth rinse use in children (Randomized double-blind controlled clinical trial). Dent Res J (Isfahan). 2011; 8(Suppl1): S58-S63.

16. McDonald S, Prenzler PD, Antolovich M, Robards K. Phenolic content and antioxidant activity of olive extracts. Food Chem 2001;73: 73-84.

17. Standards. Methods for dilution antimicrobial susceptibility tests for bacteria that National Committee for Clinical Laboratory grow aerobically. Approved standard M7-A6. National Committee for Clinical Laboratory Standards. Wayne: Pa; 2003.

18. Naderi N J, Niakan M, Kharazi Fard MJ, Zardi S. Antibacterial Activity of Iranian Green and Black Tea on Streptococcus Mutans: An In Vitro Study. J Dent (Tehran). 2011; 8(2): 55-59.

19. Sakanaka S, Kim M, Taniguchi M, Yamamoto T. Antibacterial Substances in Japanese Green Tea Extract against Streptococcus mutans, a Cariogenic Bacterium. Agric Biol Chem 1989:53(9):2307-11 20. You SQ. Study on feasibility of Chinesegreen tea polyphenols (CTP) for preventing dental caries. Zhonghua Kou Qiang Yi Xue Za Zhi 1993;28(4):197-9, 254.

21. Subramaniam $P$, Eswara U, Maheshwar Reddy KR. Effect of different types of tea on Streptococcus mutans: an in vitro study. Indian J Dent Res 2012;23(1):43-8.

22. Smullen J, Koutsou G, Foster H, Zumbé A, Storey D. The antibacterial activity of plant extracts containing polyphenols against Streptococcus mutans. Caries Res 2007;41(5):342-9.

23. Rasheed A, Haider M. Antibacterial activity of Camellia sinensis extracts against dental caries. Arch pharm Res 1998;21(3):34852.

24. Li JY, Zhan L, Barlow J, Lynch RJ, Zhou XD, Liu TJ. Effect of tea polyphenol on the demineralization and remineralization of enamel in vitro. Sichuan Da Xue Xue Bao Yi Xue Ban 2004; 35(3):364-6.

25. Hambire CU, Jawade R, Patil A, Wani VR, Kulkarni AA, Nehete PB.Comparing the antiplaque efficacy of $0.5 \%$ Camellia sinensis extract, $0.05 \%$ sodium fluoride, and $0.2 \%$ chlorhexidine gluconate mouthwash in children. $J$ Int Soc Prev Community Dent. 2015;5(3):218-26.

\section{Conflict of Interest: None Declared.}

Copyright: (c) the author(s) and publisher. IJMRP is an official publication of Ibn Sina Academy of Medieval Medicine \& Sciences, registered in 2001 under Indian Trusts Act, 1882.

This is an open access article distributed under the terms of the Creative Commons Attribution Non-commercial License, which permits unrestricted non-commercial use, distribution, and reproduction in any medium, provided the original work is properly cited.

Cite this article as: Najmeh Akhlaghi, Maryam Mehnati, Maryam Hajiahmadi. In Vitro Antimicrobial Activities against Streptococcus Mutans: A Comparative Study of Green Versus Black Tea Extracts and $0.2 \%$ Chlorhexidine and Fluoride. Int J Med Res Prof. 2016; 2(5):11-15. 